\title{
Design Thinking For Designing the Future
}

\author{
Jennifer Ozturkeri \\ The Newman School
}

\begin{abstract}
21 st Century has reshaped our perception of disciplines, resulting in a 'fusion' of boundaries that were once distinct. The interdisciplinary studies have lent themselves to new careers that provide the services and products that reflect a blend of the knowledge and skill attributes of individual fields of study. This brings us to the question: How does one prepare for the challenge of interacting within and manipulating such an environment? One could argue that it is the responsibility of the tertiary institutions, who create the interdisciplinary programs and know the learning outcomes, to mold the student into a predetermined form. On the other hand, how realistic is it to expect the student to adopt a cross-curricular approach of thinking and skillset within a four-year program? Embracing the fact that these programs and their newer versions will be a norm of the future, we must begin preparing the students starting from their first years in formal education. Educators in primary and secondary schools around the world include interdisciplinary projects at varying depths, breadths and frequencies. These projects are aimed at allowing students to transfer their learning in one area to another. However, they are limiting in several ways: Knowledge and skill transfer can occur only if there is a corresponding application area; innovation is not factored in and teachers, not the students, determine the boundaries. Developing an interdisciplinary school curriculum using the design thinking process is my proposed solution to preparing the students for these entwined environments.
\end{abstract}

Keywords: interdisciplinary; curriculum; fusion; voice; processes 